\title{
Impact of early response on outcomes in AL amyloidosis following treatment with frontline Bortezomib
}

Sriram Ravichandran (D) ${ }^{1}$, Oliver C. Cohen ${ }^{1}$, Steven Law (iD ${ }^{1}$, Darren Foard ${ }^{1}$, Marianna Fontana ${ }^{1}$, Ana Martinez-Naharro ${ }^{1}$, Carol Whelan ${ }^{1}$, Julian D. Gillmore ${ }^{1}$, Helen J. Lachmann ${ }^{1}$, Sajitha Sachchithanantham ${ }^{1}$, Shameem Mahmood ${ }^{1}$, Philip N. Hawkins ${ }^{1}$ and Ashutosh D. Wechalekar (iD ${ }^{1 凶}$

(c) The Author(s) 2021

The outcomes in systemic AL amyloidosis are dependent on the depth of haematologic response. However, there is limited data on the impact of the speed of response on outcomes. Here we report the impact of speed of response in a cohort of AL patients treated with upfront Bortezomib. Patients seen from February 2010 until August 2019 are included in the present analysis. 1194 \& 1133 patients comprised the ITT and 1-month landmark cohorts. In the landmark cohort, 137 (11.5\%), 270 (22.6\%), 252 (21.1\%) and 352 (31.1\%) patients had a CR, VGPR, PR and NR at 1-month. Patients with $\geq$ VGPR at 1-month had significantly better survival (median not reached; at the end of 1, 2, 5,10 years, $87 \% / 92 \%, 83 \% / 87 \%, 68 \% / 72 \%$ and $63 \% / 58 \%$ of patients in CRNGPR, respectively, were alive) compared to those with a PR (median OS 60 months) or NR (median OS 32 months) $(p<0.005)$. At 1-month, patients with CR and iFLC $<20 \mathrm{mg} / \mathrm{l}$ had a significantly better survival compared to CR and iFLC $>20 \mathrm{mg} / \mathrm{l}(p=0.005)$. Reaching $\geq$ VGPR at 1-month significantly improved survival in all Mayo disease stages. In conclusion, patients achieving an early deep haematologic response have a significantly superior survival irrespective of cardiac involvement.

Blood Cancer Journal (2021)11:118; https://doi.org/10.1038/s41408-021-00510-7

\section{INTRODUCTION}

Systemic immunoglobulin light chain amyloidosis $(\mathrm{AL})$ is a rare disorder of protein misfolding caused by an underlying monoclonal Bcell or plasma cell dyscrasia. About two-thirds of patients have cardiac involvement at diagnosis, the most important prognostic determinant [1]. The amyloidogenic immunoglobulin-free light chain is the determinant of the disease. In the absence of any proven therapies to remove the deposited fibril protein, treatment remains focused on clonal suppression. With the introduction of novel anti-plasma cell therapy, there has been a marked improvement in the survival of $\mathrm{AL}$ patients over the last decade [2]. Bortezomib-based regimes are the current first-line standard of care. While achieving a profound suppression of the amyloidogenic light chain has been shown to correlate with better survival [3-5], the impact of the speed of response on outcomes remains less well studied. In a selected group of AL patients, the Greek Amyloidosis group and we have previously shown that achieving an early response is associated with better outcomes $[6,7]$. Conceivably, a slower response could be associated with organ progression before the response is achieved and adversely impact outcomes, whilst a rapid response may avoid this.

In this study, we report the impact of speed of response on outcomes in a large cohort of unselected AL patients treated with upfront Bortezomib-based regimes.

\section{PATIENTS AND METHODS}

\section{Patients}

All patients from the ALchemy study (an ongoing prospective observational study of newly diagnosed AL amyloidosis) seen at the UK National Amyloidosis Centre from February 2010 until August 2019 and treated with upfront
Bortezomib are included in the present analysis. The ALchemy study is approved by the relevant institutional review board, and all patients provided written informed consent per the declaration of Helsinki. Patients with a difference between involved and uninvolved free light chain (dFLC) $<20 \mathrm{mg} / \mathrm{l}$ at diagnosis were excluded due to a lack of validated response criteria in this patient group $[8,9]$.

Details of the investigations at diagnosis/follow-up, schedule of follow-up at NAC and treatments is available in the supplementary appendix.

Organ involvement and responses were defined by ICC $[10,11]$. The European modification of Mayo 2004 staging was used, with Stage III stratified into Illa (NT-proBNP $<8500 \mathrm{ng} / \mathrm{L}$ ) and IIlb (NT-proBNP $\geq 8500 \mathrm{ng} /$ L) [12]. We also collected data on response assessment, survival status, and dates of death/last known follow-up.

We report the responses based on the validated criteria reported by Palladini et al. $[3,13]$. As per the standard follow-up protocol, serum-free light chain (FLC) and serum monoclonal protein levels (when present) were monitored at the beginning of each chemotherapy cycle. In this study, we report haematologic responses at 1,3 and 6 months and outcomes based on these responses. Organ responses are reported based on the criteria published by Palladini et al. [3]. and Gertz et al. [11].

Due to challenges in postal transport of monthly urine samples, we defined responses at 1 and 3 months based on serum immunofixation and serum-FLCs alone. The response was defined according to the validated criteria at 6 months (including urine immunofixation). Very good partial response (VGPR) was defined as a dFLC $<40 \mathrm{mg} / \mathrm{l}$, and partial response (PR) was defined as a $50 \%$ decrease in the dFLC over the baseline. Patients with $a<50 \%$ decrease in dFLC over baseline were classified as no response (NR). Recent studies have shown that patients achieving a deep suppression of the amyloidogenic light chain have a superior response $[4,5]$. Therefore, we also identified patients who achieved a dFLC $<10 \mathrm{mg} / \mathrm{l}$ and involved free light chain (iFLC) $<$ $20 \mathrm{mg} / \mathrm{l}$.

\footnotetext{
${ }^{1}$ National Amyloidosis Centre, University College London (Royal Free Campus), London, UK. ${ }^{凶}$ email: a.wechalekar@ucl.ac.uk
} 
Overall survival (OS) was calculated from the date of diagnosis to the time of death, or the last known follow-up. Patients who were alive were censored at the date of their last known follow-up.

\section{Statistical analysis}

We performed all statistical analysis using SPSS version 27 (IBM Inc, USA). The method of Kaplan and Meier was used to generate survival curves. The two-sided log-rank test was used to assess statistical significance between survivals. All reported $\mathrm{p}$ values are two-sided with the conventional significance of $\leq 0.05$. The independent $t$-test was used to test for a significant difference in means between the subjects. We used regression models (Cox proportional hazards model and binary logistic regression) to analyse the impact of early haematologic response on survival and organ function. We analysed all data on an intent to treat basis. We also performed a landmark analysis of survivors at 1, 3 and 6 months. Organ responses were assessed in the 12-month landmark cohort.

\section{RESULTS}

A total of 1276 patients received upfront Bortezomib from Feb 2010 until the end of Aug 2019. Eighty-two patients had dFLC < $20 \mathrm{mg} / \mathrm{l}$ at diagnosis and are excluded from this analysis. 1194 patients comprise the intention to treat cohort (ITT cohort). Table 1 lists the baseline characteristics of these patients. 61, 156 and 246 patients died within 1, 3 and 6 months of diagnosis. 1133, 1038 and 948 patients comprised the 1-month, 3-month and 6month landmark cohorts, respectively. 1011 (89.2\%), 985 (94.9\%) and 915 (96.5\%) patients were evaluable in the respective cohorts (Fig. 1A).

The median age was 66 years (range $29-88$ ) years. $66.2 \%, 67.3 \%$ and $11.6 \%$ of patients had cardiac, renal, and liver involvement, respectively. The median $\mathrm{dFLC}$, NT- proBNP and proteinuria were $208.5 \mathrm{mg} / \mathrm{l}$ (range 20.1-15898 mg/L), $1393 \mathrm{ng} / \mathrm{l}$ (range 4-93602 ng/ L) and $2.9 \mathrm{gm} / 24 \mathrm{~h}$ (range $0-36 \mathrm{~g} / 24 \mathrm{~h}$ ), respectively. Patients received a median of six cycles of chemotherapy (range 1-12 cycles). Eighty-seven patients underwent an autologous stem cell transplant (ASCT).

\section{Haematologic response}

The haematologic responses at 1,3, and 6 months are shown in Fig. 1B. In the ITT cohort 137 (11.5\%), 270 (22.6\%), 252 (21.1\%), and $413(34.6 \%)$ patients had a CR, VGPR, PR and NR at 1 month, respectively. There was a progressive improvement in the proportion of patients with a deeper response ( $\geq V G P R)$ from $34.1 \%$ at one month to $57.1 \%$ and $65 \%$ at 3 and 6 months, respectively.

\section{Impact of speed and depth of response on overall survival}

Table 2 shows patients' overall survival in the ITT, 1-month, 3month and 6-month landmark cohorts, stratified by their haematologic response. The median OS of the ITT cohort was 56 months (95\% Cl 47.02-64.97 months). In the ITT cohort, at 1month, patients with a CR or VGPR had significantly better survival than those with a PR or NR $(p<0.005)$ (Fig. 2A). Similar results were seen at 3 and 6 months (Figs. SA1 and SA2 in supplementary appendix). In the landmark cohorts $(1,3$ and 6 months), the median OS of patients achieving a CR or VGPR was significantly better than those with a partial or no response $(p<0.005)$ (Fig. 2B-D). There was no significant difference in survival between patients with $C R$ and VGPR in all cohortsmedian OS not reached in both groups in all cohorts, $p=0.753$ (ITT), $p=0.593$ (1-month landmark), $p=0,230$ (3-month landmark) and $p=0.070$ (6-month landmark), respectively.

\section{Early deep response ( $\geq$ VGPR at 1-month) versus late deep response ( $\geq$ VGPR at $\mathbf{6}$ months): impact on overall survival} Since a deep haematologic response at 1 month following treatment impacted outcomes, we analysed the survival of
Table 1. Baseline characteristics.

\begin{tabular}{|c|c|}
\hline & $N=1194$ \\
\hline Baseline characteristics & $\begin{array}{l}\text { Median (range) or } n \text { / } \\
N(\%)\end{array}$ \\
\hline Age, y & $66(29-88)$ \\
\hline Gender & $\begin{array}{l}\text { Male: } 713 \text { (59.7); Female: } \\
481 \text { (40.3) }\end{array}$ \\
\hline \multirow[t]{2}{*}{ Performance status } & ECOG 0-2: 1117 (93.6) \\
\hline & ECOG > 2: $77(6.4)$ \\
\hline Cardiac involvement & $791(66.2)$ \\
\hline \multirow{4}{*}{$\begin{array}{l}\text { Mayo stage (European modification of } \\
\text { Mayo stage) }\end{array}$} & I: $183(15.3)$ \\
\hline & II: 409 (34.3) \\
\hline & IIla: 418 (35) \\
\hline & IIIb: 184 (15.4) \\
\hline NT-proBNP, ng/L & $1393(4-93602)$ \\
\hline High-sensitivity cardiac troponin $\mathrm{T}, \mathrm{ng} / \mathrm{L}$ & $57(1-742)$ \\
\hline Left ventricular wall thickness, mm & $13(8-24)$ \\
\hline Renal involvement & $802(67.3)$ \\
\hline Serum creatinine, $\mu \mathrm{mol} / \mathrm{L}$ & $96(26-1124)$ \\
\hline Proteinuria, $\mathrm{g} / 24 \mathrm{~h}$ & $2.9(0-36)$ \\
\hline Liver involvement & $139(11.6)$ \\
\hline Alkaline Phosphatase, U/L & $90(16-2389)$ \\
\hline Gl Involvement & $48(4)$ \\
\hline $\begin{array}{l}\text { Autonomic nervous system } \\
\text { involvement }\end{array}$ & $82(6.9)$ \\
\hline Peripheral nervous system involvement & $85(7.1)$ \\
\hline Soft tissue involvement & $187(15.7)$ \\
\hline \multirow[t]{6}{*}{ Heavy chain isotype } & IgG: 386 (32.3) \\
\hline & $\lg A: 161$ (13.5) \\
\hline & IgM: 38 (3.2) \\
\hline & IgD: $9(0.8)$ \\
\hline & LC: 312 (26.1) \\
\hline & None: 288 (24.1) \\
\hline Serum monoclonal protein, $\mathrm{g} / \mathrm{L}$ & 8 (IF-45) \\
\hline \multirow[t]{2}{*}{ Light chain isotype } & Kappa: 258 (21.6) \\
\hline & Lambda: 936 (78.4) \\
\hline $\mathrm{dFLC}, \mathrm{mg} / \mathrm{L}$ & $208.5(20.1-15898)$ \\
\hline
\end{tabular}

$d F L C$ the difference between involved and uninvolved light chains, ECOG Eastern co-operative oncology group, NT-proBNP N-terminal pro-brain natriuretic peptide

patients achieving an early deep response (at 1 month) and compared them with those who had not achieved this response at 1 month but had reached a deep response later (at 6 months). There were 915 evaluable patients with response data at 1 and 6 months. 501 patients (54.75\%) had not achieved a CR or VGPR at 1-month. 224/501 (44.71\%) patients improved their response to $C R$ or VGPR at 6 months. Using the Cox proportional hazards model, patients who achieved a deep haematologic response early had significantly better survival than those who achieved a deep haematologic response laterHR $1.454,95 \% \mathrm{Cl} 1.039-2.033(p=0.029)$. The median OS was not reached in the early responders versus 74 months in the late responders $(p=0.027)$ (Fig. SA3 in supplementary appendix). 
A

Patients treated with upfront Bortezomib $\mathrm{n}=1276$

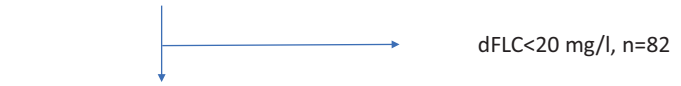

Intent to Treat Cohort, $\mathrm{n}=1194$

Deaths in the $1^{\text {st }}$ month, $\mathrm{n}=61$

1-Month Landmark Cohort, $\mathrm{n}=1133$

Evvaluable patients $=1011(89.2 \%)\}$

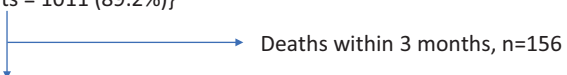

3-Month Landmark Cohort, $\mathrm{n}=1038$

\{Evaluable patients $=985(94.9 \%)\}$

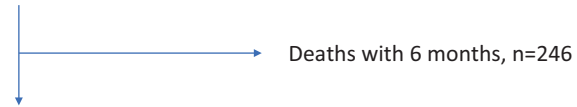

6-Month Landmark Cohort, $\mathrm{n}=948$

\{Evaluable patients $=915$ (96.5\%)

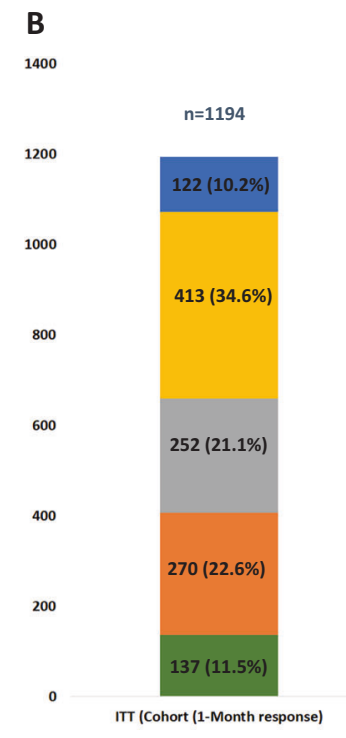

Haematologic response at 1, 3 and 6 months
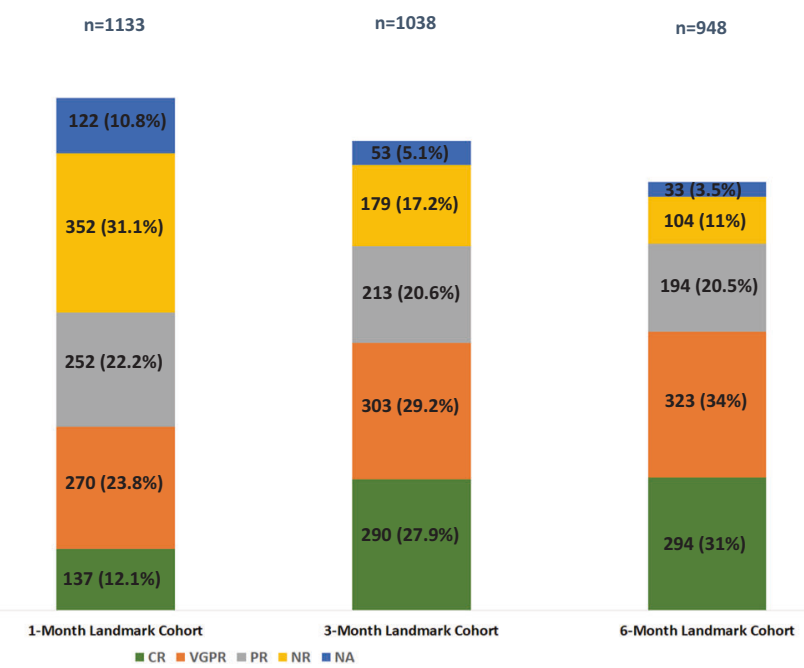

Fig. 1 This figure shows the flow of patients in the study and responses acheived at different time points in the study. A Consort diagram. 1276 patients were treated with upfront Bortezomib from Feb 2010 to Aug 2019. 82/1276 (6.4\%) had dFLC < $20 \mathrm{mg} / \mathrm{l}$ and are excluded from the analysis. There are 1194, 1133, 1038, and 948 patients in the ITT, 1-month, 3-month and 6-month landmark cohorts. B Shows the haematologic responses 1 month, 3 months and 6 months. In the ITT cohort $137(11.5 \%), 270(22.6 \%), 252(21.1 \%)$ and $413(34.6 \%)$ patients had a CR, VGPR, PR and NR at 1 month, respectively. There was a progressive improvement in the proportion of patients with a deeper response ( $\geq$ VGPR) from $34.1 \%$ at one month to $57.1 \%$ and $65 \%$ at 3 and 6 months, respectively.

\section{Impact of deep suppression of the amyloidogenic light chain on outcomes}

We also analysed outcomes in CR/VGPR patients based on the degree of suppression of the amyloidogenic light chain ( $\mathrm{dFLC}<$ $10 \mathrm{mg} / \mathrm{l}$ and $\mathrm{iFLC}<20 \mathrm{mg} / \mathrm{l})$. Figure $3 \mathrm{~A}$ shows the distribution of patients with CR/VGPR and dFLC $<10 \mathrm{mg} / \mathrm{l} / \mathrm{iFLC}<20 \mathrm{mg} / \mathrm{l}$ at 1 and 6 months.

In the 1-month landmark cohort, patients with CR and iFLC < $20 \mathrm{mg} / \mathrm{l}$ at 1-month had significantly better survival compared to patients with CR and iFLC $>20 \mathrm{mg} / \mathrm{l}$-median not reached in both groups ( $p=0.005)$ (Fig. 3B). There was no significant difference in survival of CR at 1-month based on $\mathrm{dFLC}<$ or $>10 \mathrm{mg} / \mathrm{L}$ (Fig. SA4 in supplementary appendix). Also, there was no significant difference in survival of VGPR at 1-month based on their dFLC or iFLC level.

In the 6-month landmark cohort, we analysed patients' survival stratified by the following variables- $C R$, less than $C R$ but $\mathrm{dFLC}<$ $10 \mathrm{mg} / \mathrm{l}$ or $\mathrm{iFLC}<20 \mathrm{mg} / \mathrm{l}$. The survival of patients with $\mathrm{CR}$
( $n=294)$ was compared to those who were not in CR but had $\mathrm{dFLC}<10 \mathrm{mg} / \mathrm{l}(n=155)$ or iFLC $<20 \mathrm{mg} / \mathrm{l}(n=111)$. There was no significant difference in survival between patients with $C R$ and those not in CR but had a dFLC $<10 \mathrm{mg} / \mathrm{l}$-median OS not reached in both groups $(p=0.617)$ (Fig. SA5 in supplementary appendix). Similarly, there was no significant difference in survival between patients with $C R$ and those not in $C R$ but had achieved an iFLC $<20 \mathrm{mg} / \mathrm{l}$-median OS not reached in both groups ( $p=$ 0.233) (Fig. SA6 in supplementary appendix).

Finally, for a more granular understanding of how deep suppression of the amyloidogenic light chain affects survival, we compared the following groups of patients based on their dFLC $\mathrm{CR}+\mathrm{dFLC}<10 \mathrm{mg} / \mathrm{l}, \mathrm{VGPR}+\mathrm{dFLC}<10 \mathrm{mg} / \mathrm{l}, \mathrm{CR}+\mathrm{dFLC}>10 \mathrm{mg} /$ I, VGPR + dFLC > $10 \mathrm{mg} / \mathrm{l}$; and iFLC levels $-\mathrm{CR}+\mathrm{iFLC}<20 \mathrm{mg} / \mathrm{l}$, VGPR $+\mathrm{iFLC}<20 \mathrm{mg} / \mathrm{l}, \mathrm{CR}+\mathrm{iFLC}>20 \mathrm{mg} / \mathrm{l}$ and VGPR $+\mathrm{iFLC}>$ $20 \mathrm{mg} / \mathrm{l}$ (Fig. 3C, D).

Patients with CR or VGPR and $\mathrm{dFLC}<10 \mathrm{mg} / \mathrm{l}$ had a significantly better survival compared to CR or VGPR and dFLC $>10 \mathrm{mg} / \mathrm{l}$ 


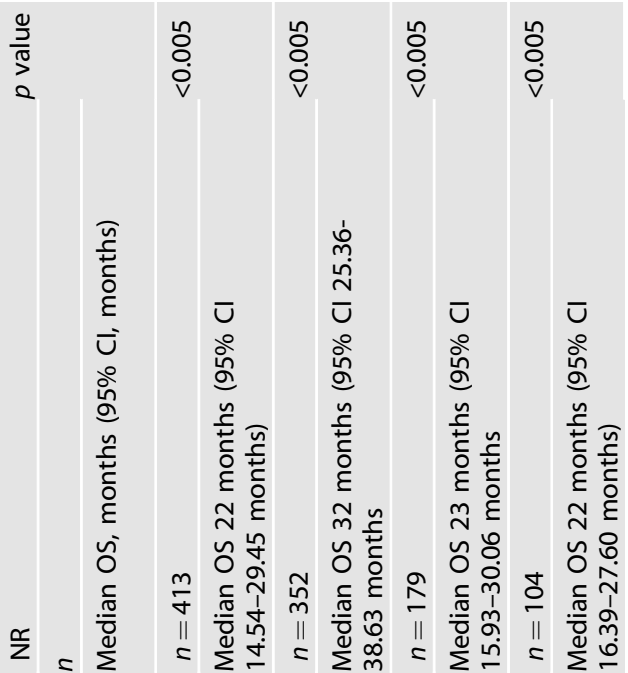

$(p<0.005)$. There was no significant difference in survival between patients with CR $+\mathrm{dFLC}<10 \mathrm{mg} / \mathrm{l}$ and VGPR $+\mathrm{dFLC}<10 \mathrm{mg} / \mathrm{l}-$ median not reached in both groups $(p=0.693)$. Patients with VGPR and $\mathrm{dFLC}<10 \mathrm{mg} / \mathrm{l}$ had a significantly better survival when compared to CR and dFLC > $10 \mathrm{mg} / \mathrm{l}(p=0.002)$-median not reached vs. 72 months (95\% Cl 38.94-105.05 months) (Fig. 3C).

Similarly, patients with a CR or VGPR and iFLC $<20 \mathrm{mg} / \mathrm{l} \mathrm{had} \mathrm{a}$ significantly better survival compared to CR or VGPR and iFLC > $20 \mathrm{mg} / \mathrm{l}(p<0.005)$. There was no significant difference in survival between patients with $\mathrm{CR}+\mathrm{iFLC}<20 \mathrm{mg} / \mathrm{l}$ and VGPR $+\mathrm{iFLC}<$ $20 \mathrm{mg} / \mathrm{l}-$ median not reached in both groups $(p=0.683)$. Patients with VGPR $+\mathrm{iFLC}<20 \mathrm{mg} / \mathrm{l}$ had a significantly better survival when compared to $\mathrm{CR}$ and iFLC $>20 \mathrm{mg} / \mathrm{l}(p=0.005)$-median not reached vs. 74 months (95\% Cl 65.60-82.40) (Fig. 3D).

\section{Impact of early response on overall survival stratified by Mayo disease stage}

We analysed outcomes based on 1-month response (1-month landmark cohort) stratified by the Mayo stage. As we found no significant difference between OS for patients with CR and VGPR, they were analysed as a group and compared to patients with less than a VGPR (PR or NR). We found that patients with $\geq$ VGPR at 1month had significantly better survival than patients with $<$ VGPR $(p<0.005)$. The improved survival was seen across all Mayo stages. The median OS of patients achieving $\geq$ VGPR vs < VGPR was: Mayo stage I: median not reached vs was 88 months $(95 \% \mathrm{Cl}$ 72.65-103.35 months); Mayo stage II: median not reached vs 58 months (95\% Cl 41-74.99 months); Mayo stage Illa median 74 months vs 30 months ( $95 \% \mathrm{Cl} 23.69-36.30$ months) and Stage III b: median 31 months ( $95 \% \mathrm{Cl} 11.05-50.95$ months) vs 7 months (95\% Cl 3.03-10.96 months), respectively (Fig. 4A-D). Of patients with Mayo stage I disease reaching $\geq$ VGPR at 1 month, 99\%, 99\%, $94 \%$ and $82 \%$ were alive at the end of 1, 2, 5 and 10 years (from landmark point). Similarly, $96 \%, 90 \%, 77 \%$ and $68 \%$ of Mayo stage II patients with $\geq$ VGPR at 1 month were alive at the end of 1, 2, 5 and 10 years (from landmark point).

\section{Impact of early deep response on organ function}

Finally, we analysed the impact of early haematologic response on organ function in the 12-month landmark cohort. 841 patients were available for analysis in the 12-month landmark cohort. 498 (59.2\%) patients had cardiac involvement, and 586 (69.7\%) had renal involvement. As there were only 90 (10.7\%) patients with liver involvement, we have not analysed the liver response in the present cohort.

Cardiac response was evaluable in 394/498 (79\%) and 356/498 (71.5\%) patients at 6 and 12 months, respectively. $103(26.1 \%)$ and 194 (54.5\%) patients had a cardiac response at 6 and 12 months, respectively. $188(37.8 \%)$ and $269(54 \%)$ patients had $\geq$ VGPR and $<$ VGPR at 1-month, respectively. At 6 months, 51/188 (27.1\%) patients with $\geq$ VGPR at 1-month had a cardiac response compared to $44 / 269$ (16.4\%) patients with < VGPR. At 12 months, $87 / 188(46.3 \%)$ patients with $\geq$ VGPR at 1-month had a cardiac response compared to $94 / 269$ (34.9\%) patients with < VGPR.

Renal response was evaluable in 449/586 (76.6\%) and 458/586 (78.2\%) patients at 6 and 12 months, respectively. $99(22 \%)$ and $115(25.2 \%)$ of patients had renal response at 6 and 12 months, respectively. 266/586 (45.4\%) and 287/586 (49\%) patients had $\geq$ VGPR and < VGPR, respectively. At 6 months, 55/266 (20.7\%) patients with $\geq$ VGPR at 1-month had a renal response compared to $41 / 287$ (14.3\%) patients with < VGPR. At 12 months, 80/266 (30.1\%) patients with $\geq$ VGPR at 1-month had a renal response compared to $31 / 287$ (10.8\%) patients with < VGPR.

Patients who had $\geq$ VGPR at 1 month had significantly higher odds of having a cardiac (OR 1.839, 95\% Cl 1.147-2.948, $p=0.011$ ) or renal (OR 1.577, 95\% Cl 0.997-2.492, $p=0.05$ ) response at 6 months. Similarly, patients who had $\geq$ VGPR at 1 month had significantly higher odds of having a cardiac (OR $1.565,95 \% \mathrm{Cl}$ 


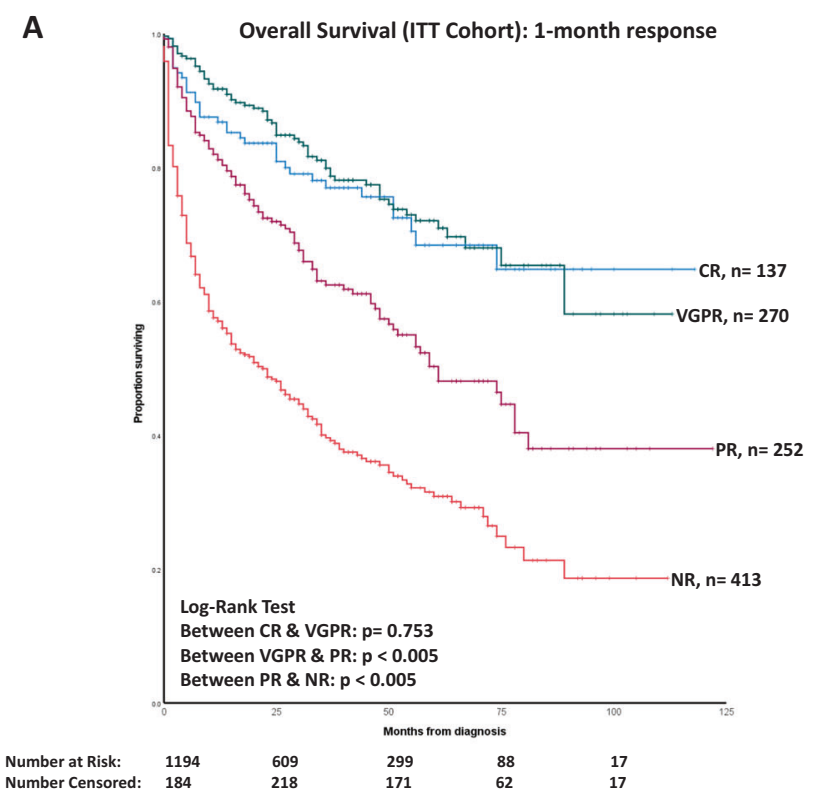

C

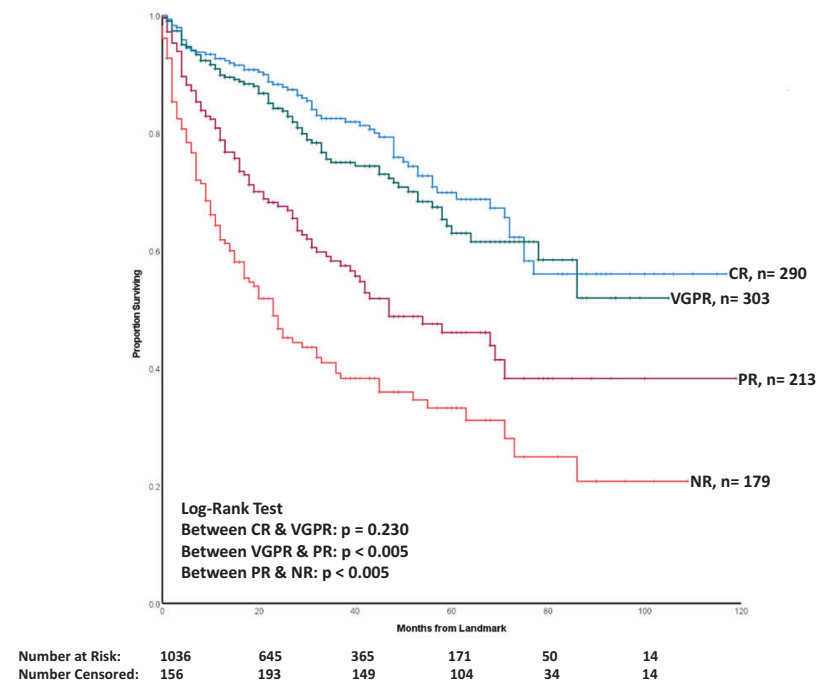

B

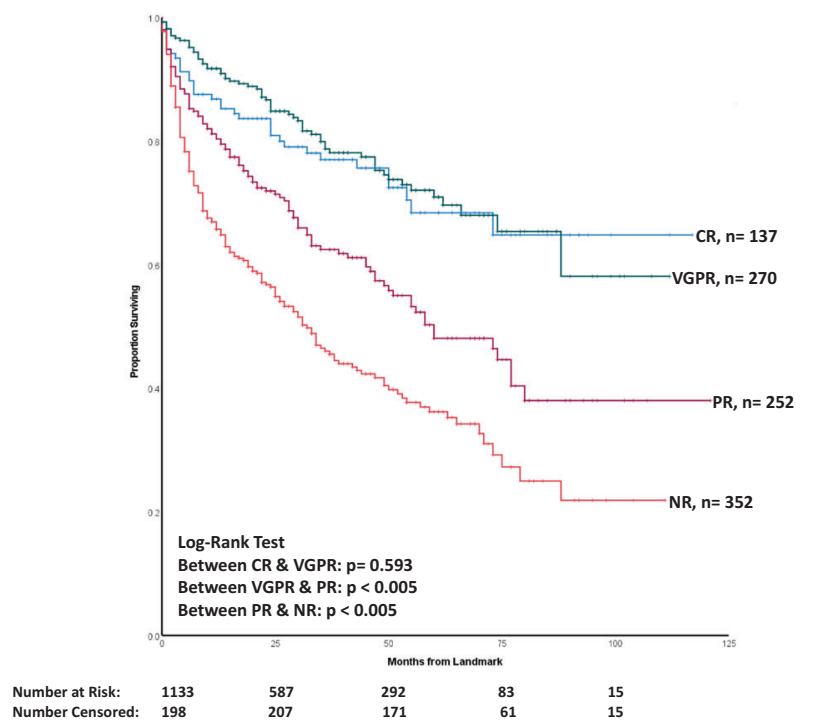

D

Overall Survival (6-Month Landmark): 6-month response

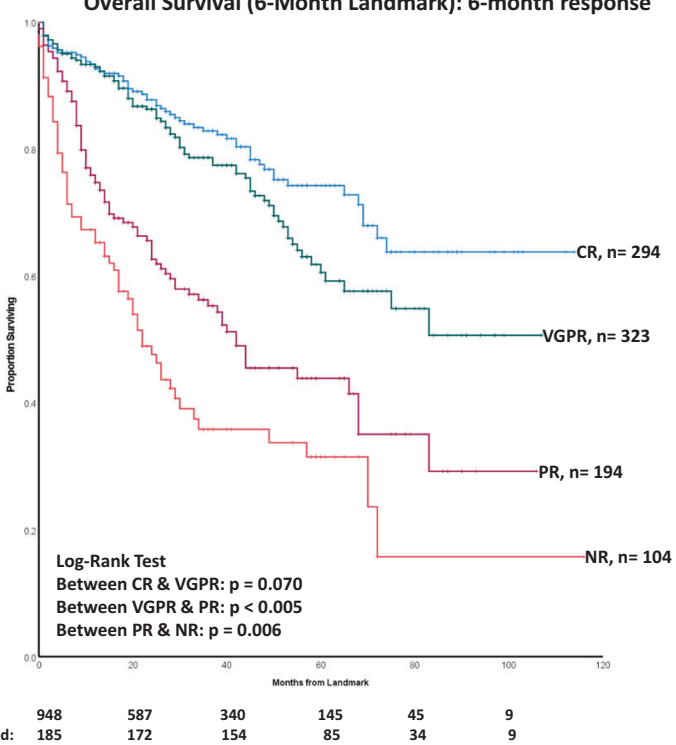

Fig. 2 This figure shows overall survival for the intention to treat (ITT), 1 month, 3 months and 6 months landmark cohorts stratified by depth of haematologic response. A Kaplan-Meier curve showing the impact of 1-month haematologic response on OS in the ITT cohort. There was no significant difference in survival between CR and VGPR at 1 month-median not reached in both groups ( $p=0.753$ ). 87\%, 83\%, $68 \%$ and $63 \%$ of patients with a CR at 1 month were alive at the end of 1,2, 5 and 10 years, respectively. $92 \%, 87 \%, 71 \%$ and $59 \%$ of patients with a VGPR at 1 month were alive at the end of 1, 2, 5 and 10 years, respectively. In contrast, the median OS of patients with PR and NR at 1 month was 61 months $(95 \% \mathrm{Cl} 43.42-78.57$ months, $p<0.005)$, and 22 months $(95 \% \mathrm{Cl} 14.54-29.45$ months, $P<0.005)$, respectively. B Kaplan-Meier curve showing the impact of 1-month haematologic response on OS in the 1-month landmark cohort. There was no significant difference in survival between CR and VGPR at 1 month-median not reached in both groups $(p=0.593) .87 \%, 83 \%, 68 \%$ and $63 \%$ of patients with a CR at 1 month were alive at the end of 1,2,5 and 10 years (from landmark point), respectively. 92\%, 87\%, 72\% and 58\% of patients with a VGPR at 1 month were alive at the end of 1,2,5 and 10 years (from landmark point), respectively. In contrast, the median OS of patients with PR and NR at 1 month was 60 months $(95 \% \mathrm{Cl} 42.42-77.57$ months, $p<0.005)$ and 32 months $(95 \% \mathrm{Cl} 25.36-38.63$ months, $P<$ 0.005), respectively. C Kaplan-Meier curve showing overall survival based on the haematologic response at 3 months in the 3-month landmark cohort. There was no significant difference in survival between CR and VGPR at 3 months-median not reached in both groups $(p=0.230)$. $93 \%, 88 \%, 69 \%$ and $55 \%$ of patients with a CR at 3 months were alive at the end of 1, 2, 5 and 10 years (from landmark point), respectively. $91 \%, 84 \%, 65 \%$ and $51 \%$ of patients with a VGPR at 3 months were alive at the end of 1, 2, 5 and 9 years (from landmark point), respectively. In contrast, the median OS of patients with PR and NR at 3 months was 47 months $(95 \% \mathrm{Cl} 27.51-66.48$ months, $p<0.005)$ and 23 months $(95 \%$ Cl 15.93-30.06 months, $p<0.005$ ), respectively. D Kaplan-Meier curve showing overall survival based on the haematologic response at 6 months in the 6-month landmark cohort. There was no significant difference in survival between CR and VGPR at 6 months-median not reached in both groups $(p=0.070) .93 \%, 88 \%, 74 \%$ and $63 \%$ of patients with a CR at 6 months were alive at the end of $1,2,5$ and 10 years (from landmark point), respectively. $93 \%, 86 \%, 61 \%$ and $51 \%$ of patients with a VGPR at 6 months were alive at the end of $1,2,5$ and 10 years (from landmark point), respectively. In contrast, the median OS of patients with PR and NR at 6 months was 42 months (95\% CI 27.91-56.09 months, $p<0.005)$ and 22 months (95\% Cl 16.39-27.60 months, $p=0.006)$, respectively. 
A

Number of patients with deep suppression of light chains

700

600

500

400

300

200

100

o

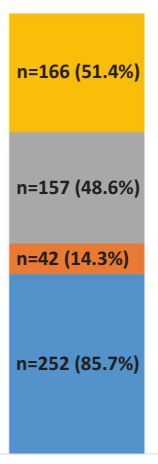

6-Month Landmark Cohort

1-Month Landmark Cohort
6-Month Landmark Cohort

B

Impact of low iFLC (<20 mg/l) on patients with CR at 1 month (1-Month landmark Cohort)

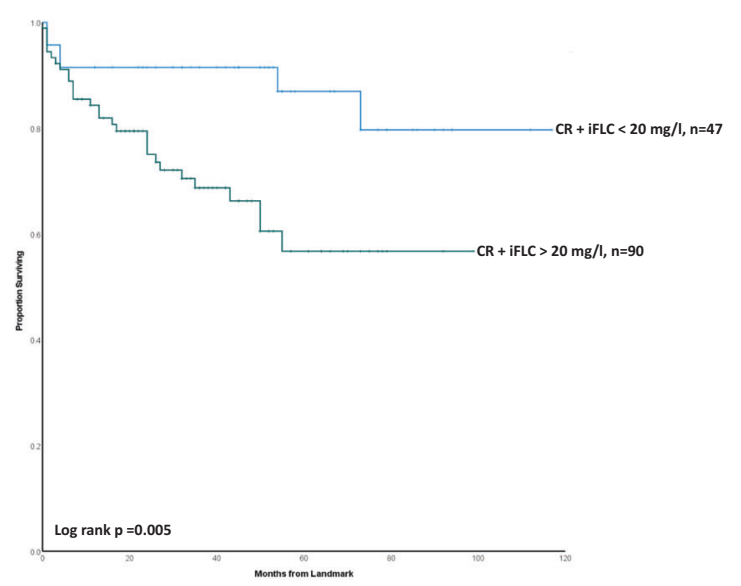

C Impact of $\mathrm{dFLC}<10 \mathrm{mg} / \mathrm{l}$ at 6 months on Survival (6-Month Landmark Cohort)

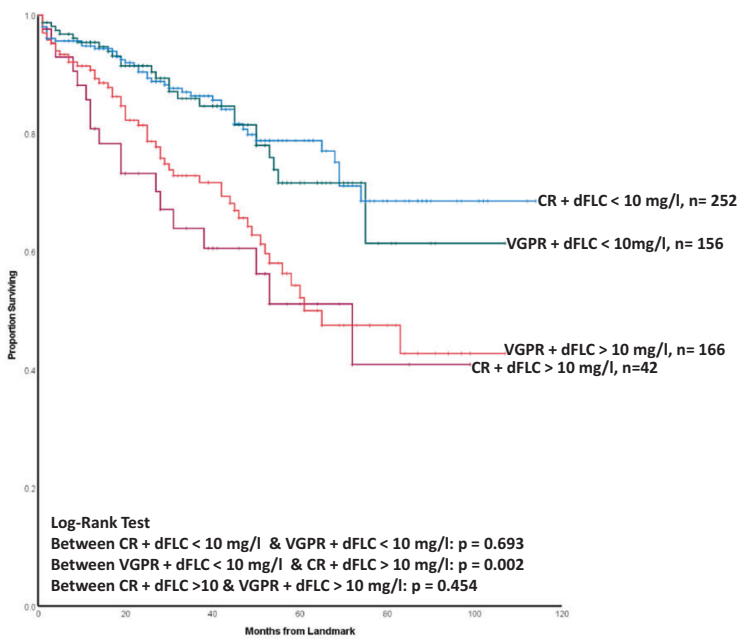

D Impact of iFLC $<20 \mathrm{mg} / \mathrm{l}$ at 6 months on Survival (6-Month Landmark Cohort)

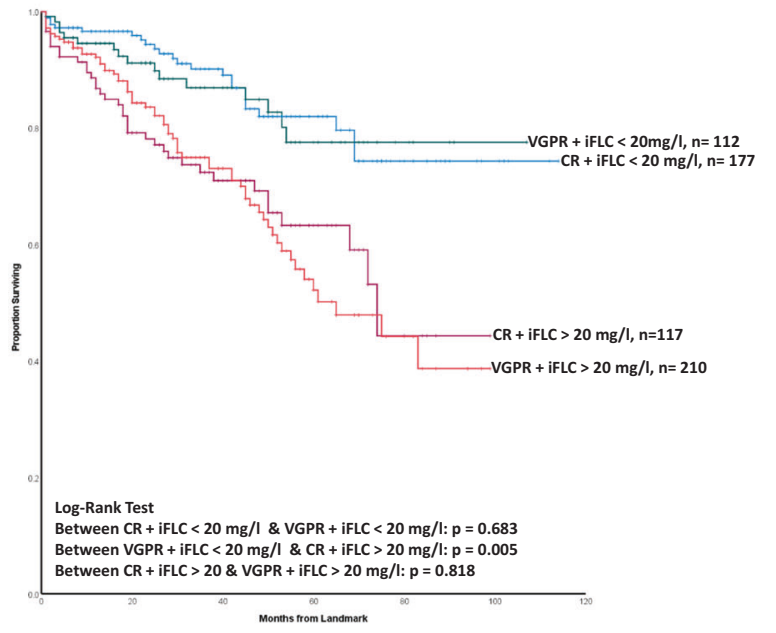

$1.005-2.437, p=0.047)$ or renal (OR 3.560, 95\% Cl 2.227-5.693, $P<$ $0.005)$ response at 12 months.

We also compared the odds of organ response at 12 months in patients with early deep response and those who achieve a deep response later. There was no significant difference in the odds of cardiac response at 12 months between early and late responders -OR 1.294, 95\% Cl 0.770-2.174, $p=0.330$. However, early responders had significantly better odds of achieving a renal response at 12 months than late responders-OR $2.790,95 \% \mathrm{Cl}$ $1.565-4.973, p=0.001$. 
Fig. 3 This figure shows patients acheiving a deep light chains suppresion (dFLC $<10 \mathrm{mg} / \mathrm{L}$ or ifLC $<20$ mg/L) and outcomes stratified by deep light chain suppression (or not). A Shows the distribution of patients with CR/VGPR and deep FLC suppression (dFLC $<10 \mathrm{mg} / \mathrm{l}$ or iFLC $<20 \mathrm{mg} / \mathrm{l}$ ) at 1 and 6 months. At 1 month, $60.6 \%$ and 39.3\% patients with CR and VGPR had dFLC < 10 mg/l, respectively. The corresponding figures at 6 months were $85.7 \%$ and $48.6 \%$, respectively. $34.3 \%$ and $33 \%$ of patients with CR and VGPR had iFLC < $20 \mathrm{mg} / \mathrm{l}$ at $1 \mathrm{month}$. The corresponding figure at 6 months is $60.2 \%$ and $35 \%$, respectively. B Kaplan-Meier curve showing the impact of low ifLC (<20 mg/l) on patients with $C R$ at 1-month. Patients with $C R$ and iFLC $<20 \mathrm{mg} / \mathrm{l}$ at 1-month had significantly better survival compared to patients with $C R$ and iFLC $>20 \mathrm{mg} / \mathrm{l}$ - median not reached in both groups $(p=0.005)$. C Kaplan-Meier curve showing the impact of $\mathrm{dFLC}<10 \mathrm{mg} / \mathrm{l}$ in patients with CR/VGPR at 6 months. There was no significant difference in survival between patients with CR $+\mathrm{dFLC}<10 \mathrm{mg} / \mathrm{l}$ and VGPR $+\mathrm{dFLC}<$ $10 \mathrm{mg} / \mathrm{l}$ - median not reached in both groups $(p=0.693)$. Patients with VGPR $+\mathrm{dFLC}<10 \mathrm{mg} / \mathrm{l}$ had a significantly better survival when compared to patients with CR and dFLC $>10 \mathrm{mg} / \mathrm{l}(p=0.002)$-median not reached vs. 72 months ( $95 \% \mathrm{Cl} 38.94-105.05$ months). There was no significant difference in survival between patients with CR $+\mathrm{dFLC}>10 \mathrm{mg} / \mathrm{l}$ and VGPR $+\mathrm{dFLC}>10 \mathrm{mg} / \mathrm{l}(p=0.454)$-median $72 \mathrm{months}$ (95\% Cl 38.94-105.05 months) vs. 61 months (95\% Cl 38.07-83.93 months). D Kaplan-Meier curve showing the impact of iFLC < 20 mg/l in patients with CR/VGPR at 6 months. There was no significant difference in survival between patients with CR $+\mathrm{iFLC}<20 \mathrm{mg} / \mathrm{l}$ and VGPR + iFLC $<20 \mathrm{mg} / \mathrm{l}-$ median not reached in both groups $(p=0.683)$. Patients with VGPR $+\mathrm{iFLC}<20 \mathrm{mg} / \mathrm{l}$ had a significantly better survival when compared to patients with $\mathrm{CR}$ and iFLC $>20 \mathrm{mg} / \mathrm{l}(p=0.005)$-median not reached vs. 74 months $(95 \% \mathrm{Cl} 65.60-82.40)$. There was no significant difference in survival between patients with CR $+\mathrm{iFLC}>20 \mathrm{mg} / \mathrm{l}$ and VGPR $+\mathrm{iFLC}>20 \mathrm{mg} / \mathrm{l}(p=0.818)-\mathrm{median} 74 \mathrm{months}(95 \%$ Cl $65.60-82.40)$ vs. 65 months ( $95 \% \mathrm{Cl} 46.81-83.18$ months).

\section{DISCUSSION}

This study assesses the impact of early clonal response on survival in a large, unselected cohort of patients with $\mathrm{AL}$ amyloidosis treated with frontline bortezomib. We show that patients who achieve a deep clonal response ( $\geq$ VGPR) within 1 month have a significantly better outcome that appears to be driven by deep suppression of the amyloidogenic light chain. Patients who achieve an early deep response have a superior survival and better organ responses than those who achieve a deep response later. The key finding is that benefit of rapid response is seen across all disease stages.

In systemic AL amyloidosis, a rapid reduction in the amyloidogenic light chains is desirable to stop the amyloidogenic pathway early. Studies in myeloma have shown that patients who respond early have a poorer outcome [14-16], possibly due to suppression of a highly proliferative plasma cell population in the marrow [17], prone to clonal evolution, leading to an early relapse. However, AL amyloidosis, with usually a modest plasmacytosis and different biology of the plasma cells, this may not be the case $[3,18,19]$.

There is limited data on the impact of rapid response on outcomes in AL amyloidosis. In two small studies, including a highly selected patient population, we showed that patients achieving an early and deep haematologic response have better overall survival and renal outcome, respectively $[6,7]$. A study by the Greek amyloidosis group [20] suggested that deep haematologic response within one month had a median OS of 9.5 years vs 3.9 years and 1.8 years for patients with PR or NR, respectively. The present study extends these results showing that a deep and rapid haematologic response improves outcomes with or without cardiac involvement. We show that the improvement in survival is seen, possibly to a greater extent, in those with no cardiac involvement and early to moderate cardiac involvement. A rapid response may avoid organ progression in early-stage patients. Due to a lack of data on organ involvement each month, this study has a limitation in being unable to report on organ progression at earlier time points.

The international amyloidosis society consensus guidelines validated response criteria in 2012 (updated in 2020) and showed that patients with a complete response $(\mathrm{aCR})$ had better overall survival than those with VGPR or lesser responses $[3,13]$. Over the last few years, we and others have shown that a deeper FLC response is also associated with better outcomes based on reaching dFLC $<10 \mathrm{mg} / \mathrm{L}$ [4] or iFLC of $<10 \mathrm{mg} / \mathrm{L}$ [5] and $<20 \mathrm{mg} / \mathrm{L}$ [21], respectively. In the current cohort, we found no difference in the outcomes of early CR vs VGPR patients. We also analysed the data in this study based on the suppression of the amyloidogenic light chain (either dFLC $<10 \mathrm{mg} / \mathrm{L}$ or iFLC $<20 \mathrm{mg} / \mathrm{L}$ ) for patients with or without $\mathrm{aCR}$, showing significant improvement in survival for patients where the FLC was below the dFLC/iFLC threshold.
The difference between these data and previous publications needs to be explored further in collaborative studies but may be related to use bortezomib in all patients in the current cohort compared to a smaller proportion in previous publications [21]. These data suggest that depth of FLC response is important in outcomes and additionally utility, if any, of lower dFLC or iFLC in addition to aCR should be formally validated.

In the current data, only $1 / 3^{\text {rd }}$ of the patients in our study had achieved a deep response at 1 month with standard Bortezomib-based therapy; therefore, there is a need for more effective and rapidly acting treatments to improve the current standard of care. In the Andromeda phase III prospective trial of CyBorD with or without daratumumab $[22,23]$, the median time to $\geq$ VGPR was 17 days for the CyBorD with Daratumumab compared to 25 days for the CyBorD combination. Whilst the current data from this study do not show any survival benefit, and longer-term follow data are awaited with interest. Until more effective combinations become routinely available, the impact of early response on modification of therapy needs to be considered cautiously. These (and previous data) are very clear that patients with suboptimal early response have worse outcomes. The crucial prospective data on the impact of early change in therapy is lacking. In the UK, current guidelines and practice recommend switching therapy in non- or suboptimal responders at three months [24, 25]. These data have two observations. Firstly, patients who have a less deep response at 1 month (not yet reached a VGPR) have a significantly poorer outcome, and secondly, the depth of responses improves over time. Switching therapy too early may mean the best benefit is not obtained and, potentially well-tolerated therapies are abandoned for second-line regimes. The increasing cost of therapy means that decisions also have a health-economic angle in most health care systems limiting access to therapies. On the other hand, waiting two or three months in anticipation of a better response leads to loss of vital time while the proteotoxic and amyloidogenic pathway remains active-an argument in favour of early switching. In a complex disease like $\mathrm{AL}$, decision making needs to be much more nuanced and individualised with attention to the patient's clinical status and the trajectory of the FLCs. Our practice now is to measure serum-FLCs frequently (once a week at least for the initial cycles) and consider therapy modification for those cases where a partial response is not achieved by 1 month and, for those with >PR at one month, where patients have <VGPR by 2 months.

The present data needs to be interpreted within the limitations of the study. This is a retrospective cohort, and we did not assess the full organ function every month, and there is limited baseline bone marrow information. All patients were treated by local 
A

Mayo Stage I, 1-month response: $\geq$ VGPR vs $<$ VGPR
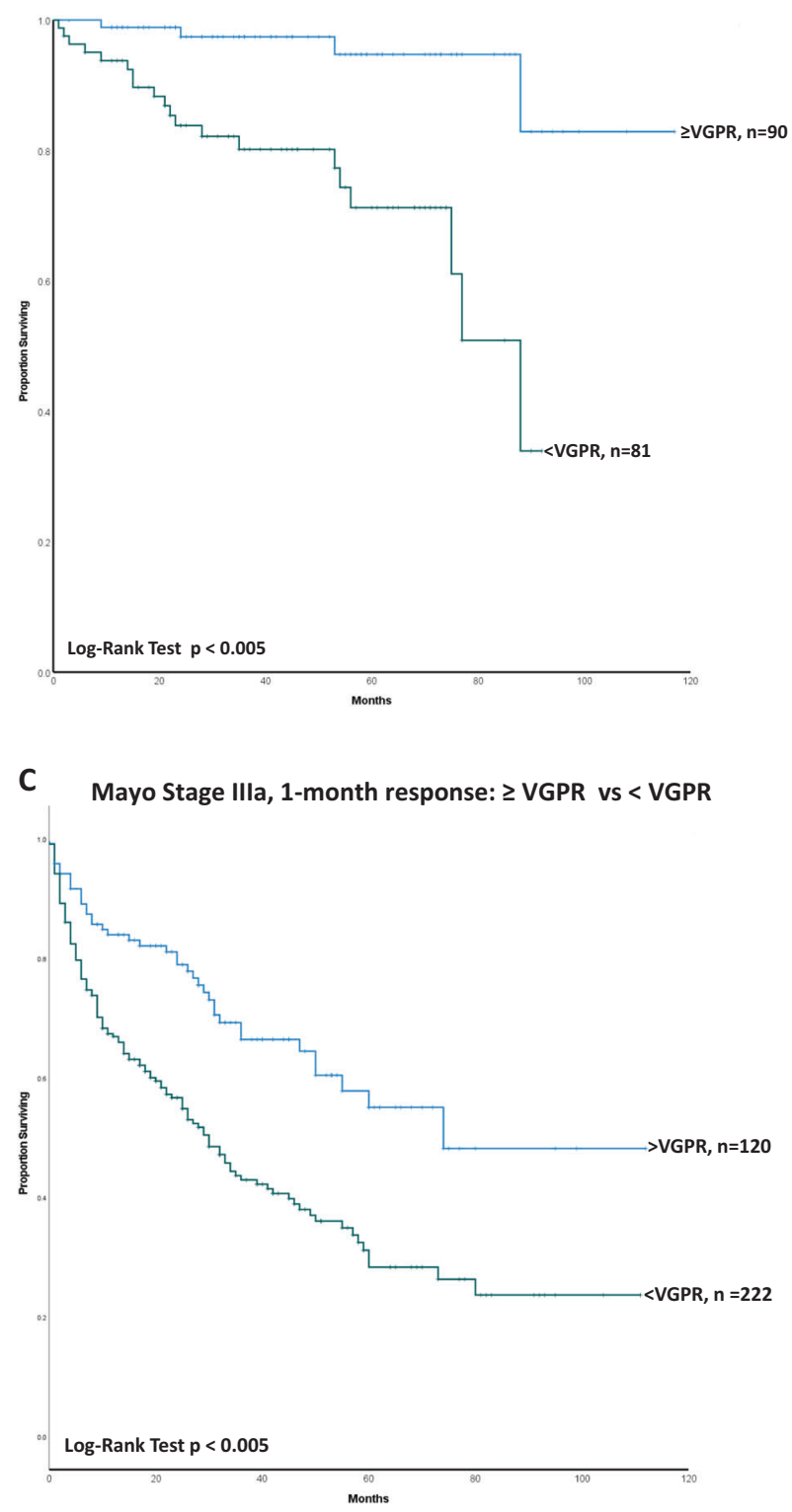

B

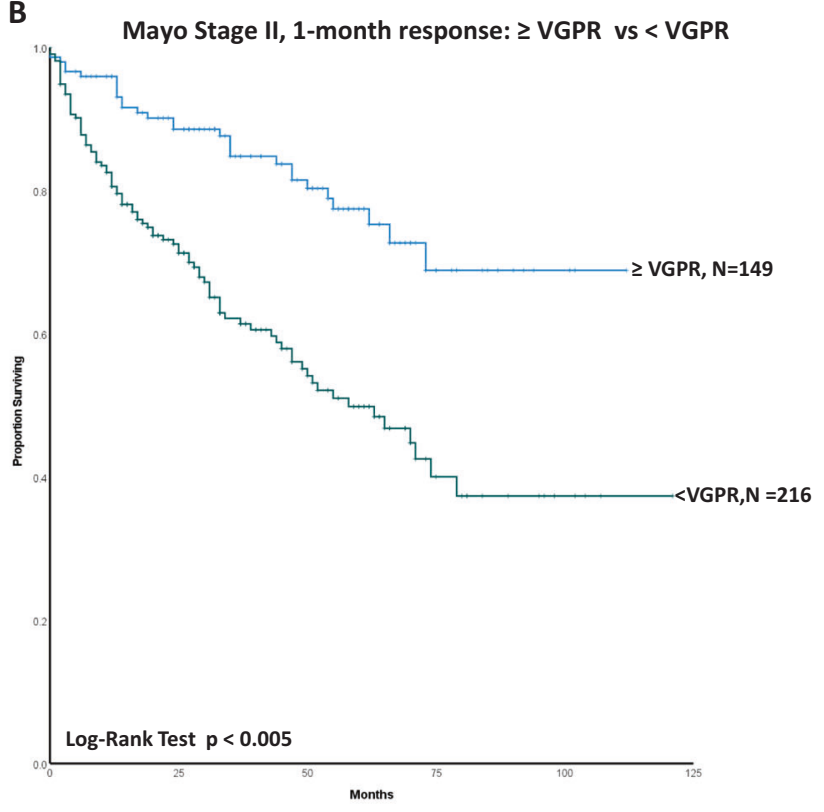

D Mayo Stage IIIb, 1-month response: $\geq$ VGPR vs $<$ VGPR

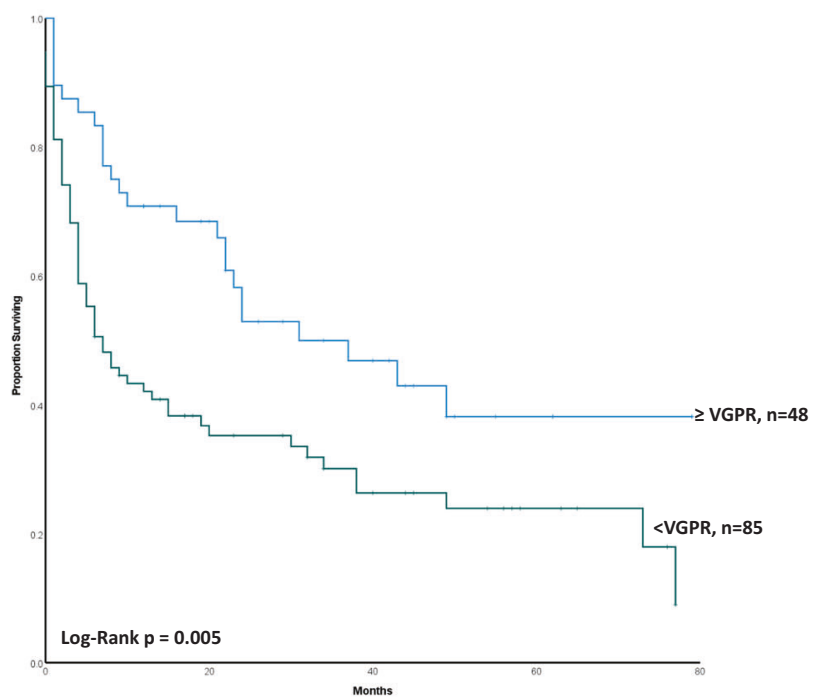

Fig. 4 This figure shows the impact of early response on survival stratified by baseline disease (Mayo) stage showing an improvement in outcomes with deeper responses across all stages. A Kaplan-Meier curve showing overall survival of Mayo stage 1 patients, stratified by their haematologic response at 1 month ( $\geq$ VGPR Vs $<$ VGPR). The median OS of patients with $\geq$ VGPR was not reached when compared to 88 months (95\% Cl 72.65-103.35 months) in patients with $<$ VGPR $(P<0.005)$. B Kaplan-Meier curve showing overall survival of Mayo stage 2 patients, stratified by their haematologic response at 1 month ( $\geq$ VGPR vs $<$ VGPR). The median OS of patients with $\geq$ VGPR was not reached when compared to 58 months $(95 \% \mathrm{Cl} 41-74.99$ months) in patients with $<$ VGPR $(P<.005)$. C Kaplan-Meier curve showing overall survival of Mayo stage 3 patients, stratified by their haematologic response at 1 month ( $\geq$ VGPR vs $<$ VGPR). The median OS of patients with $\geq$ VGPR was median 74 months when compared to 30 months (95\% Cl 23.69-36.30 months) in patients with $<$ VGPR $(P<0.005)$. D Kaplan-Meier curve showing overall survival of Mayo stage 3B patients, stratified by their haematologic response at 1 month ( $\geq$ VGPR vs $<$ VGPR). The median OS of patients with $\geq$ VGPR was 31 months (95\% Cl 11.05-50.95 months) when compared to 7 months (95\% Cl 3.03-10.96 months) in patients with $<$ VGPR $(P<0.005)$.

hospitals. Although treatments were given with nationally agreed protocols based on multidisciplinary advice from the National Amyloidosis Center, the doses of the individual chemotherapy agents were at the discretion of the treating teams, based on the patient's clinical status. There is no data on the impact of early switching of therapy on outcomes.

In conclusion, the results from the present study show that patients achieving an early and deep haematologic response have improved survival in AL amyloidosis. Crucially, the deep early responses improve outcomes across all disease stages. The impact of this early response seems to be driven by the reduction of serum-FLCs. Frequent FLC measurement and early assessment for treatment changes are important. Regimens capable of inducing a rapid and profound light chain response are on the horizon and need early adoption. The impact of switching treatment early in slow responders needs further prospective evaluation. 


\section{REFERENCES}

1. Dispenzieri A, Gertz MA, Kyle RA, Lacy MQ, Burritt MF, Therneau TM, et al. Serum cardiac troponins and $\mathrm{N}$-terminal Pro-Brain natriuretic peptide: a staging system for primary systemic amyloidosis. J. Clin. Oncol. 2004;22:3751-7.

2. Ravichandran S, Lachmann HJ, Wechalekar AD. Epidemiologic and survival trends in amyloidosis, 1987-2019. N. Engl. J. Med. 2020;382:1567-8.

3. Palladini G, Dispenzieri A, Gertz MA, Kumar S, Wechalekar A, Hawkins PN, et al. New criteria for response to treatment in immunoglobulin light chain amyloidosis based on free light chain measurement and cardiac biomarkers: impact on survival outcomes. J. Clin. Oncol. 2012;30:4541-9.

4. Manwani R, Cohen O, Sharpley F, Mahmood S, Sachchithanantham S, Foard D, et al. A prospective observational study of 915 patients with systemic AL amyloidosis treated with upfront bortezomib. Blood. 2019;134:2271-80.

5. Godara A, Toskic D, Rosenthal B, Varga C, Kugelmass A, Zhou P, et al. In systemic light-chain amyloidosis complete and very good partial responses are not enough: involved free light chain (iFLC) Levels $<10 \mathrm{mg} / \mathrm{L}$ are associated with optimal long-term survival. Blood. 2019;134:4369.

6. Manwani R, Foard D, Mahmood S, Sachchithanantham S, Lane T, Quarta C, et al. Rapid hematologic responses improve outcomes in patients with very advanced (stage IIlb) cardiac immunoglobulin light chain amyloidosis. Haematologica. 2018;103:e165-e8.

7. Rezk T, Lachmann HJ, Fontana M, Sachchithanantham S, Mahmood S, Petrie A, et al. Prolonged renal survival in light chain amyloidosis: speed and magnitude of light chain reduction is the crucial factor. Kidney Int. 2017;92:1476-83.

8. Dittrich T, Bochtler T, Kimmich C, Becker N, Jauch A, Goldschmidt H, et al. AL amyloidosis patients with low amyloidogenic free light chain levels at first diagnosis have an excellent prognosis. Blood. 2017;130:632-42.

9. Milani P, Basset M, Russo F, Foli A, Merlini G, Palladini G. Patients with light-chain amyloidosis and low free light-chain burden have distinct clinical features and outcome. Blood. 2017;130:625-31.

10. Comenzo RL, Reece D, Palladini G, Seldin D, Sanchorawala V, Landau H, et al. Consensus guidelines for the conduct and reporting of clinical trials in systemic light-chain amyloidosis. Leukemia. 2012;26:2317-25.

11. Gertz MA, Comenzo R, Falk RH, Fermand JP, Hazenberg BP, Hawkins PN, et al. Definition of organ involvement and treatment response in immunoglobulin light chain amyloidosis (AL): a consensus opinion from the 10th International Symposium on Amyloid and Amyloidosis. Am J. Hematol. 2005;79:319-28.

12. Wechalekar AD, Schonland SO, Kastritis E, Gillmore JD, Dimopoulos MA, Lane $T$, et al. A European collaborative study of treatment outcomes in 346 patients with cardiac stage III AL amyloidosis. Blood. 2013;121:3420-7.

13. Palladini G, Schönland SO, Sanchorawala V, Kumar S, Wechalekar A, Hegenbart U, et al. Clarification on the definition of complete haematologic response in lightchain (AL) amyloidosis. Amyloid. 2021;28:1-2.

14. Tandon N, Sidana S, Rajkumar SV, Gertz MA, Buadi FK, Lacy MQ, et al. Outcomes with early response to first-line treatment in patients with newly diagnosed multiple myeloma. Blood Adv. 2019;3:744-50.

15. van Rhee F, Bolejack V, Hollmig K, Pineda-Roman M, Anaissie E, Epstein J, et al. High serum-free light chain levels and their rapid reduction in response to therapy define an aggressive multiple myeloma subtype with poor prognosis. Blood. 2007;110:827-32.

16. Yan Y, Mao X, Liu J, Fan H, Du C, Li Z, et al. The impact of response kinetics for multiple myeloma in the era of novel agents. Blood Adv. 2019;3:2895-904.

17. Boccadoro M, Marmont F, Tribalto M, Fossati G, Redoglia V, Battaglio S, et al. Early responder myeloma: kinetic studies identify a patient subgroup characterised by very poor prognosis. J. Clin. Oncol. 1989;7:119-25.

18. Bochtler T, Hegenbart U, Kunz C, Benner A, Kimmich C, Seckinger A, et al. Prognostic impact of cytogenetic aberrations in $A L$ amyloidosis patients after high-dose melphalan: a long-term follow-up study. Blood. 2016;128:594-602.

19. Greipp PR, San Miguel J, Durie BG, Crowley JJ, Barlogie B, Bladé J, et al. International staging system for multiple myeloma. J. Clin. Oncol. 2005;23:3412-20.
20. Kastritis E, Fotiou D, Theodorakakou F, Dialoupi I, Migkou M, Roussou M. et al. Timing and impact of a deep response in the outcome of patients with systemic light chain (AL) amyloidosis. Amyloid. 2020;28:3-11.

21. Milani P, Basset M, Foli A, Nuvolone M, Ripepi J, Bozzola $M$, et al. The quest for indicators of profound hematologic response in $\mathrm{AL}$ amyloidosis: complete response remains the optimal goal of therapy. Blood. 2019;134:1901.

22. Efstathios Kastritis GP, Monique C Minnema, et al. Subcutaneous daratumumab + cyclophosphamide, bortezomib, and dexamethasone (CyBorD) in patients with newly diagnosed light chains (AL) amyloidosis: primary results from the phase 3 ANDROMEDA study. EHA 25 Virtual2020.

23. Palladini G, Kastritis E, Maurer MS, Zonder JA, Minnema Mc, Wechalekar AD, et al Daratumumab plus CyBorD for patients with newly diagnosed $A L$ amyloidosis: safety run-in results of ANDROMEDA. Blood. 2020;136:71-80.

24. Wechalekar AD, Gillmore JD, Bird J, Cavenagh J, Hawkins S, Kazmi M, et al. Guidelines on the management of AL amyloidosis. Br J. Haematol. 2015;168:186-206.

25. Wechalekar AD, Goodman HJB, Lachmann HJ, Offer M, Hawkins PN, Gillmore JD. Safety and efficacy of risk-adapted cyclophosphamide, thalidomide, and dexamethasone in systemic AL amyloidosis. Blood. 2006;109:457-64.

\section{AUTHOR CONTRIBUTIONS}

S.R. collected/analysed the data and wrote the manuscript. O.C., S.L., D.F., M.F., A.M.N., C.W., J.D.G., H.J.L., S.S., S.M. and P.N.H. reviewed and approved the final manuscript. A. D.W. supervised the study, reviewed, and approved the final manuscript.

\section{COMPETING INTERESTS}

A.D.W. has received honoraria from Janssen, GSK, Celgene, and Takeda. The other authors do not have any conflict of interest to disclose.

\section{ADDITIONAL INFORMATION}

Supplementary information The online version contains supplementary material available at https://doi.org/10.1038/s41408-021-00510-7.

Correspondence and requests for materials should be addressed to A.D.W.

Reprints and permission information is available at http://www.nature.com/reprints

Publisher's note Springer Nature remains neutral with regard to jurisdictional claims in published maps and institutional affiliations.

\begin{abstract}
Open Access This article is licensed under a Creative Commons Ay
adtribution 4.0 International License, which permits use, sharing, appropriate credit to the original author(s) and the source, provide a link to the Creative Commons license, and indicate if changes were made. The images or other third party material in this article are included in the article's Creative Commons license, unless indicated otherwise in a credit line to the material. If material is not included in the article's Creative Commons license and your intended use is not permitted by statutory regulation or exceeds the permitted use, you will need to obtain permission directly from the copyright holder. To view a copy of this license, visit http://creativecommons. org/licenses/by/4.0/.
\end{abstract}

(c) The Author(s) 2021 